\title{
VAZIOS URBANOS E A HABITAÇÃO SOCIAL: Uma possibilidade para São Miguel do Oeste, Santa Catarina
}

Urban voids and the Housing of social interest: a possibility to São Miguel do Oeste, Santa Catarina

Vacíos urbanos y la habitación social: Una posibilidad para São Miguel do Oeste, Santa Catarina

Cristiano Togni

Acadêmico do curso de Arquitetura e Urbanismo da Universidade do Oeste de Santa Catarina - UNOESC. E-mail: cristiano.togni@gmail.com

\section{Patrícia Dalmina de Oliveira}

Professora do curso de Arquitetura e Urbanismo da Universidade do Oeste de Santa Catarina, Mestre em Urbanismo, História e Arquitetura da Cidade pela Universidade Federal de Santa Catarina. E-mail: patricia.oliveira@unoesc.edu.br)

\section{Sergio Torres Moraes}

Professor doutor do curso de Arquitetura e Urbanismo da Universidade Federal de Santa Catarina. E-mail: sergiomoraes@arq.ufsc.br 


\section{INTRODUÇÃO}

O lar é o lugar para onde todo ser humano quer retornar ao final do dia, espaço onde expressa sua identidade, ampara sua privacidade e desenvolve o sentimento de pertencimento. Em contraposto a ideia de lar, a habitação social tem sido tratada como quesito meramente quantitativo, resumindo-se a amparar apenas a necessidade de abrigo, esquecendo que este espaço deve possuir relação com os serviços urbanos coletivos, bem como, possuir infraestrutura indispensável para as necessidades dos usuários, além de perpassar a identidade de quem o habita.

A busca pela viabilidade econômica das habitações sociais ao longo dos anos levou a rigidez e a padronização dos projetos, ocasionando espaços de difícil apropriação. Neste sentido, a qualidade, tanto funcional quanto construtiva é precária e muitas vezes os locais de implantação são inadequados. Exemplo disso são os conjuntos habitacionais construídos pelo poder público nas áreas periféricas das grandes cidades brasileiras desde a década de 1970 sem os serviços urbanos básicos, o que acaba contribuindo para a segregação sócio espacial (PALERMO, 2009; REIS, LAY, 2010).

A localização, portanto, é um fator que tem grande influência na qualidade das habitações sociais. Atualmente, a maioria das cidades brasileiras, alinhadas com a legislação do Estatuto da Cidade $^{1}$, utiliza o zoneamento urbano para o ordenamento do território. Neste zoneamento, existe as Zonas Especiais de Interesse Social (ZEIS) que são áreas demarcadas para as habitações de baixa renda. Não obstante a lei exigir que sejam demarcadas em áreas providas de infraestrutura urbana, estas são geralmente locadas em regiões periféricas da cidade, carentes de infraestrutura básica. Locar essas habitações longe dos centros das cidades, contribui para uma expansão urbana com pouco controle, onerando o poder público e estimulando a especulação imobiliária (JOURDA, 2012).

É nesta realidade que se insere o município de São Miguel do Oeste/SC, onde as ZEIS (nomeada no município de AEIS - Áreas Especiais de Interesse Social) são alocadas na periferia do tecido urbano, apesar de haver inúmeras áreas vazias e dotadas de infraestrutura urbana adjacente à região central.

O presente artigo visa ampliar o debate sobre a relação da habitação social e a segregação social, e discutir como os chamados "vazios urbanos" ${ }^{2}$ poderiam auxiliar na busca pela sustentabilidade social dos conjuntos habitacionais. Para isso, analisou-se o município de São Miguel do Oeste, identificando a localização das suas AEIS e a relação destas com o transporte público; em um segundo momento buscou-se identificar uma área da cidade que apresenta os equipamentos comunitários necessários para a sustentabilidade social e ao mesmo tempo

\footnotetext{
${ }^{1}$ BRASIL. Estatuto da Cidade: Lei 10.257/2001 que estabelece diretrizes gerais da política urbana. Brasília, Câmara dos Deputados, 2001

2 Entende-se como vazios urbanos, os terrenos e as edificações não utilizadas, e/ou subtilizadas, localizados em tecidos consolidados, com infraestrutura e com potencial para a construção, porém que não realizam plenamente o potencial construtivo ou cumprindo sua função social (FREITAS; BARON; GABRIEL, 2015).
} 
possua diversos vazios urbanos, comprovando a hipótese de utilizar os vazios urbanos para uma habitação social mais integrada e socialmente sustentável. - Para Palermo (2009) Sustentabilidade Social é definido como a garantia de justiça social e melhoria das condições de bem-estar e de qualidade de vida do ser humano, permitindo o acesso aos serviços como educação e saúde, sendo estreitamente ligado as condições de habitação.

Para analisar a área escolhida utilizou-se os parâmetros definidos por Keeler, Burke (2010) e Farr (2016) para identificar um "bairro sustentável", que devem incluir a conectividade, ruas caminháveis, urbanização compacta com usos mistos, projetos que consideram a malha urbana, equipamentos públicos de fácil acesso por meio de transporte público, a pé ou bicicleta. Desse modo, percebe-se que a relação entre bairros sustentáveis e cidades mais compactas é importante no auxílio da diminuição da segregação espacial. Entender esse processo em cidades de pequeno porte é de fundamental importância para um espaço urbano mais igualitário e saudável.

\section{HABITAÇÃO DE INTERESSE SOCIAL}

A moradia é um dos direitos humanos fundamentais previsto no Art. 60 da Constituição Federal de 1988, que deveria direcionar o Brasil para o modelo de Estado de Bem-estar Social. O Estado de Bem-Estar Social, em inglês Welfare State, segundo Santos (2009) é definido como uma forma de regulação social entre o estado, a economia e a sociedade, em um determinado momento econômico. Estas regulamentações estão associadas às políticas públicas relacionadas aos direitos básicos, como: educação, saúde, previdência social, assistência social, habitação e integração.

Embora o Brasil possua alguma estrutura para ter o Estado de Bem-Estar social previsto pela Constituição Federal, percebe-se que a realidade em relação à habitação ainda é precária. Mesmo com o desenvolvimento de diversas políticas públicas e programas habitacionais ao longo dos últimos 70 anos, ainda há diversas famílias de baixa renda que são impossibilitadas de comprar habitações de interesse social. Um dos fatores que contribui para essa impossibilidade é a incapacidade do desenvolvimento econômico periférico de promover empregos pelo setor formal, deste modo, as famílias se sujeitam a empregos informais sem comprovação de renda, dificultando o acesso ao financiamento imobiliário, o que acaba auxiliando na situação informal de habitação (WERNA et al., 2001).

Entre os programas de habitação social realizados pelo governo federal nas últimas décadas, como a Cohab e o Programa Minha Casa Minha Vida, destaca-se os de construções de habitação em massa, financiadas pelos bancos governamentais. Tais habitações são definidas como Habitação de Interesse Social (HIS), ou seja, habitação de baixo custo voltada para a população de baixa renda. No entanto, o baixo custo não deve justificar baixa qualidade (CECCHETTO et al., 2015).

Entende-se que a condição de sustentabilidade é inerente à condição de bem-estar e de qualidade de vida do ser humano; se as necessidades essenciais do ser humano não forem atendidas não haverá sustentabilidade em qualquer esfera, seja social, ambiental ou econômica. Assim, afirma-se que o referencial de qualidade de vida está estreitamente ligado 
às condições de habitação, que não se resume somente ao abrigo, pois também se refere às relações do homem com o abrigo, no sentido da apropriação dos espaços, no suprimento das necessidades, no convívio familiar e social (SAUGO e MARTINS, 2012). Conforme Palermo (2009), esses fatores estão estreitamente ligados à condição de sustentabilidade social.

Nesse contexto, para promover a sustentabilidade social na habitação os gestores públicos devem desenvolver seus projetos em três âmbitos: social, ambiental e econômico. O âmbito social diz respeito as condições saudáveis e salubres de moradia, as relações de vizinhança, aos espaços adequados e acessíveis ao desenvolvimento de atividades individuais e coletivas, e ao transporte público. No âmbito ambiental se refere a conservação de recursos naturais, ao uso racional de energia e da água, ao uso de matéria prima renovável e das fontes de energias alternativas. Por fim, no âmbito econômico, relaciona-se ao desenvolvimento econômico, a oportunidade de geração de emprego e da gestão dos recursos produzidos. Assim, a produção das habitações no meio urbano, deverá observar essas três funções para assim cumprir seu papel social (CECCHETTO et al., 2015).

\subsection{SEGREGAÇÃO URBANA}

A segregação espacial, característica relevante das cidades brasileiras, é fruto das condições econômicas e sociais e da produção desigual do espaço urbano. Atualmente a localização das habitações sociais é determinada pelo valor do solo e pelo zoneamento urbano, o que acaba determinando o lugar dos grupos mais pobres na cidade (MOREIRA JUNIOR, 2010). De acordo com Villaça (2001) a segregação é um processo que tende a concentrar diferentes classes ou camadas sociais em regiões diferentes.

O tipo de segregação mais conhecido das cidades é o do centro em relação a periferia. $O$ primeiro, dotado de infraestrutura e serviços urbanos, ocupado pelas classes de alta renda; a segunda, - a periferia - carente de infraestrutura, afastada dos centros, e ocupada muitas vezes pelas classes de baixa renda, assim esse espaço funciona como um mecanismo de exclusão, sem opção de trabalho, transporte, lazer, cultura, o que acaba resultando numa forma de isolamento perpetuando o ciclo da pobreza (VILLAÇA, 2001).

A habitação desempenha um papel fundamental na inclusão social e qualidade de vida urbana, pois se refere às relações do homem com o abrigo, no sentido da apropriação dos espaços, no suprimento das necessidades, convívio familiar e social, sendo uma oportunidade para as camadas de baixa renda se inserirem na cidade. No entanto, a localização dessas habitações é muitas vezes definida pelas dinâmicas de desenvolvimento econômico e pelas políticas de ordenamento do espaço. Nas políticas urbanas atuais, como o Programa Minha Casa Minha Vida, busca-se muitas vezes minimizar o valor investido nas Habitações de Interesse Social (HIS), o que significa, comprar terrenos baratos, consequentemente afastados do centro da cidade (BENETTI, 2012).

Além disso, a definição das Zonas de Interesse Social (ZEIS) em planos diretores de muitas cidades brasileiras não obedece as regras do Estatuto da Cidade e reservam áreas distantes dos seus centros urbanos para as camadas de baixa renda. Como já mencionado, as habitações distantes da malha urbana consolidada, além de aumentarem os custos da cidade, 
comprometem o desenvolvimento social das famílias e estimulam a apropriação indevida do espaço (CADONÁ, TIRELLI e AREOSA, 2016).

A precária relação entre as propostas e práticas governamentais de todas as esferas, e a pouca preocupação com os problemas sociais do país colaboram para a segregação sócio espacial. Apesar das políticas habitacionais brasileiras se guiarem pela inclusão social e por uma cidade mais justa, estas ainda não lograram barrar as injustiças causadas pela segregação espacial. Portanto, repensar a locação das habitações sociais no espaço urbano e a utilização dos vazios urbanos para esse fim nasce como uma alternativa lógica para a promoção de uma cidade mais equitativa e compacta.

\subsection{VAZIOS URBANOS}

Os vazios urbanos causam um certo estranhamento nos trajetos cotidianos, em meio à agitação da cidade. Os vazios atuam como causadores de desequilíbrio e de transformação na produção e percepção do espaço urbano, despertando a sensação de que deve-se evitá-los nos percursos (BORDE, 2006).

Entende-se como vazios urbanos os terrenos e as edificações não utilizadas, e/ou subutilizadas, localizados em tecidos urbanos consolidados, com infraestrutura, e com potencial para a construção, porém que não realizam plenamente o potencial construtivo ou não cumprem sua função social (FREITA; BARON; GABRIEL, 2015). De acordo com o Art. 39 da Lei 10.257/2001, denominado Estatuto da Cidade:

A propriedade urbana cumpre sua função social quando atende às exigências fundamentais de ordenação da cidade expressas no plano diretor, assegurando o atendimento das necessidades dos cidadãos quanto à qualidade de vida, à justiça social e ao desenvolvimento das atividades econômicas, [...].

A formação dos vazios urbanos nas cidades possui diversos fatores, sendo um dos mais presentes a retenção especulativa do solo urbano. Os incorporadores ao definirem a expansão da malha urbana, acabam deixando espaços vazios visando a especulação imobiliária, sendo que a valorização dessas áreas é paga pela sociedade. Além de não trazer nenhum benefício para a coletividade, os terrenos vazios em áreas centrais são de alto custo, o que contribui para a expansão urbana nas áreas periféricas, visto que estes terrenos são mais acessíveis, aumentando assim, a segregação urbana (FREITAS; BARON; GABRIEL, 2015).

Assim, a disputa pelo uso do solo, através da especulação imobiliária e a segregação territorial são responsáveis por um ordenamento territorial desigual e excludente, criando um padrão de desenvolvimento que tem resultado na degradação socioambiental que aflige, sobretudo, as classes de menor poder aquisitivo, em condições precárias e insalubres de habitação, que coexistem com bairros com alta infraestrutura e com residências de luxo (MOREIRA JUNIOR, 2010. Uma das soluções para mitigar a segregação urbana seria então a utilização dos vazios urbanos da cidade, promovendo a densificação destes espaços. 
Vários estudos mostram que cidades ou bairros densos, ou seja, que contém usos mistos de bens e a serviços, potencializam a atividade econômica nas cidades, e geram menos deslocamentos do que locais dependentes de automóveis. A densificação das cidades deve otimizar o uso para comunidade local a equipamentos escolares, esportivos, culturais serviços públicos, comércio, além de tornar mais eficiente o transporte público e a dar a possibilidade do deslocamento a pé integrado com edificações e infraestrutura de alto desempenho (FARR, 2013), facilitando o acesso aos locais de trabalho, ao comércio, as instituições administrativas, culturais, esportivas e aos centros de saúde. (FARR, 2016; CHING e SHAPIRO, 2017). Portanto, a escolha do local para habitação de interesse social deve ser estratégica e considerar a densificação.

A inclusão social da população de baixa renda nos locais consolidados da malha urbana reduz o crescimento urbano disperso, bem como torna a cidade mais justa e igualitária. Assim, percebe-se que discutir a habitação social em vazios urbanos torna-se pertinente e é um recurso a ser utilizado pelas cidades brasileiras a fim de promover uma cidade mais sustentável.

\section{SÃO MIGUEL DO OESTE}

São Miguel do Oeste está localizado na Mesorregião do Oeste Catarinense e possui uma população estimada em 2017 de 39.793 (IBGE, 2017). Polo do Extremo Oeste Catarinense, o município chama atenção pela sua representatividade tanto na região, quanto no estado de Santa Catarina; exemplo disso é o fato de ser considerado pelo REGIC 2007 (2008), Capital Subregional nível $B$, enquanto todos os outros municípios da região são caracterizados como Centro Local.

O município para ser considerado Capital Subregional B precisa ter importância econômica, política, de serviços e de gestão empresarial para região, fato que é comprovado pela ocupação dos habitantes do município, onde 58,46\% tem ocupação ligada ao setor de comércio e serviços, $14,48 \%$ em relação industrial e apenas $12,83 \%$ ao setor agropecuário (OLIVEIRA, 2016).

A representatividade regional tem chamado a atenção da população da região, fazendo com que migração para São Miguel do Oeste tenha aumentado, sendo que entre os anos de $2000 \mathrm{e}$ 2010 a população do município aumentou $12.32 \%$. Contraposto a isso, a população rural que representava $15,26 \%$ da população total diminuiu para $11.6 \%$. Logo, a migração concentra-se no núcleo urbano do município (OLIVEIRA, 2016).

Essa migração da região, bem como, a mudança da população do meio rural para o meio urbano e o aumento da população em geral, vem sendo refletida no Déficit habitacional do município. Em 2017, o município possuía no cadastrado do setor de Habitação, 1.463 famílias de baixa renda para recebimento de habitações. Conforme de Oliveira e Black (2017) a demanda por habitações sociais no município é grande, porém, a maioria das famílias vivem em situação informal, isto é, sem registro de trabalho, ou por desemprego ou por não possuir comprovação de renda na maioria das situações, fato que dificulta a atuação legal dos órgãos públicos. 
Em São Miguel do Oeste, o Plano Diretor do Município (Lei Complementar 002/2011) no Art. 92, estabelece a utilização das As Áreas Especiais de Interesse Social (AEIS) como "[...] porções do território do Município destinadas prioritariamente à regularização fundiária, urbanização e à produção de Habitação de Interesse social (HIS) e de Habitação de Mercado Popular (HMP)." O município tem as AEIS divididas em três diferentes usos específicos:

I - AEIS I - áreas públicas ou particulares ocupadas por assentamentos de população de baixa renda, dentro das quais o Poder Público promoverá a regularização fundiária e implantação de infraestrutura ou, em caso de risco à saúde e qualidade de vida dos moradores, a relocação das famílias para outra área e a recuperação ambiental do local.

II - AEIS II - áreas públicas ou particulares ocupadas por assentamentos de população de baixa renda, dentro das quais o Poder Público promoverá a regularização fundiária e implantação de infraestrutura e a implantação de equipamentos de recreação e lazer;

III - AEIS III - áreas com terrenos não edificados e não parcelados, destinados preferencialmente à implantação de Habitação de Interesse Social, Habitação de Mercado Popular, loteamentos de interesse social e loteamentos populares, ao incentivo à instalação de comércio e serviços de caráter local e à implantação de equipamentos de recreação e lazer.

Apesar dos diferentes usos das AEIS, percebe-se pela Figura 1, que ao demarcar todas as AEIS do município ${ }^{3}$ (sem suas diferenciações), a maior parte destas se encontram nas periferias do município, algumas bem distantes das áreas dotadas de infraestrutura e equipamentos urbanos, conforme pode-se observar na figura 1.

\footnotetext{
${ }^{3}$ Optou-se por não diferenciar as AEIS nessa análise, em virtude que buscou-se entender a relação das AEIS com o tecido urbano geral da cidade.
} 
Figura 1 - Áreas Especiais de Interesse Social de São Miguel do Oeste - SC

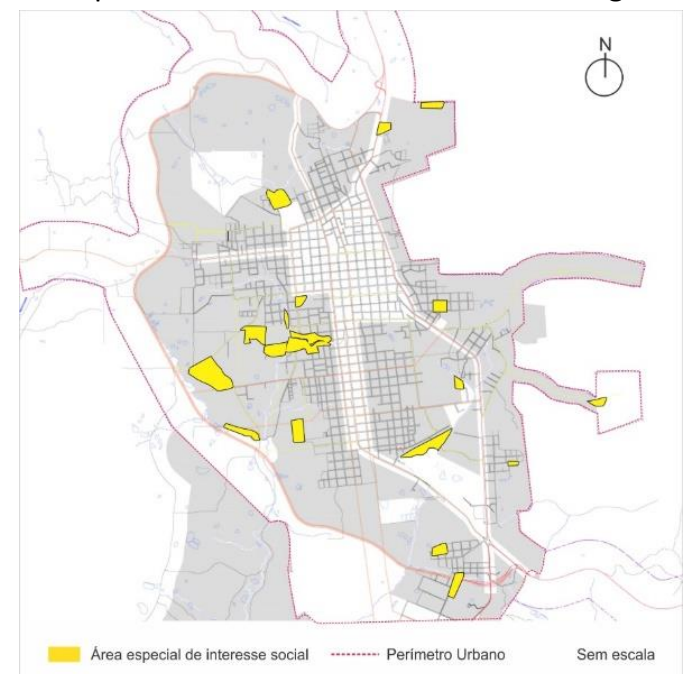

Fonte: Prefeitura de São Miguel do Oeste (2015), adaptado pelos autores.

A maioria dessas áreas não possuem acesso ao transporte público, dificultando assim, o acesso ao trabalho e contribuindo para a segregação urbana. Conforme Ferraz e Torres (apud Daiprai, 2007), para haver uma boa qualidade do transporte público a distância do ponto de ônibus deve abranger um raio de 300 metros do percurso de caminhabilidade do usuário. Na Figura 2, pode-se observar, que os raios de abrangência do transporte público não contemplam a maioria das áreas de interesse social, já que estas estão localizadas muito além deste raio de 300 metros.

Figura 2 - AEIS atual do município e Raios de abrangência pontos de ônibus

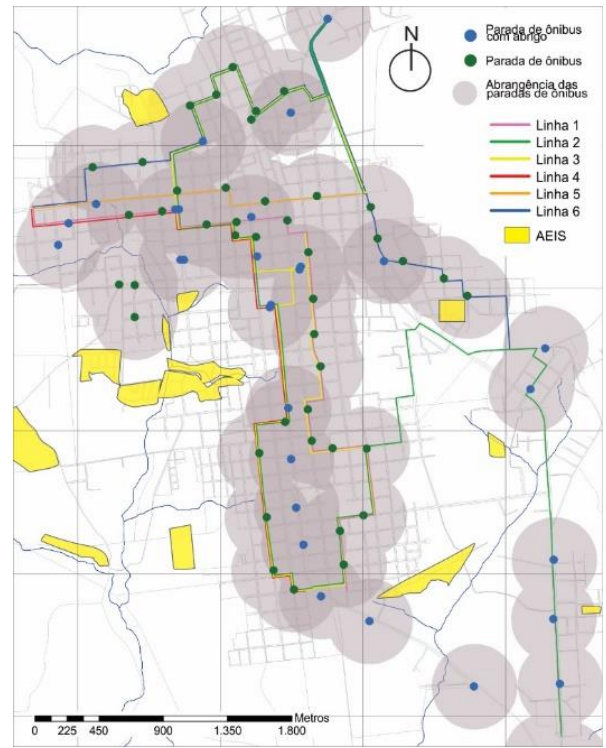

Fonte: Base de dados Prefeitura de São Miguel do Oeste (2015); Daiprai (2017), alterado pelos autores (2018)

A provisão adequada de serviços públicos é indispensável para a sustentabilidade social, logo, o transporte coletivo urbano é um dos agentes necessários para o combate à desigualdade 
social, e consequentemente, na busca de uma sociedade mais igualitária. Para Gomide (2003) a pobreza não está somente ligada as necessidades básicas - moradia, vestuário, alimentação-, mas também a falta de acesso aos serviços essenciais, ou seja, elementos como educação, saúde, transporte coletivo. Além dos direitos sociais básicos, trabalho, moradia, seguridade social, etc. Assim, percebe-se que é necessário rever a forma como as Áreas de Interesse Sociais estão sendo locadas no município e qual o incentivo para um desenvolvimento urbano nestes espaços.

Em contraponto a essa realidade, observa-se localidades no município onde há diversos equipamentos comunitários concentrados em regiões que apresentam inúmeros vazios urbanos, áreas com baixa densidade urbana e com subaproveitamento da infraestrutura existente (Figura 03).

O Plano Diretor de São Miguel do Oeste, no Art. 134, da Lei Complementar no 2/2011, aborda a seguinte definição para equipamentos comunitários: "[...] são os equipamentos de uso público de educação, cultura, saúde, lazer, segurança, assistência social, treinamento profissional, associativismo e similares, quando pertencentes ao Poder Público", e para Equipamentos Urbanos: "[...]são os equipamentos de abastecimento de água, esgoto, energia elétrica, coleta de água pluvial, rede telefônica, coleta de lixo, gás canalizado, estações de abastecimento e de tratamento de efluentes domésticos e industriais;".

Assim, para a análise da relação existente entre os equipamentos e os vazios urbanos foi buscado uma área de São Miguel do Oeste que apresentasse uma concentração de equipamentos comunitários em um raio de 500 metros e diversos vazios urbanos. A área analisada é a que contempla um equipamento comunitário de escala regional, o Hospital Regional Terezinha Gaio Basso, localizada no bairro São Gotardo. Esse equipamento teve início das obras em 2006 e inauguração em 27 de dezembro de 2010, sendo que após a sua implantação, essa localidade recebeu alguns loteamentos e edificações, porém ainda apresenta uma grande quantidade de vazios urbanos.

$\mathrm{Na}$ figura 03, pode-se observar a existência de diversos vazios urbanos nas proximidades, dotadas de infraestrutura. Estes lotes em sua maioria de propriedade privada, não são a mais de 5 anos ocupados, não cumprindo a função social do lote definida no Plano Diretor do Município. 
Figura 03 - Localização da área de análise dos equipamentos comunitários e os vazios urbanos

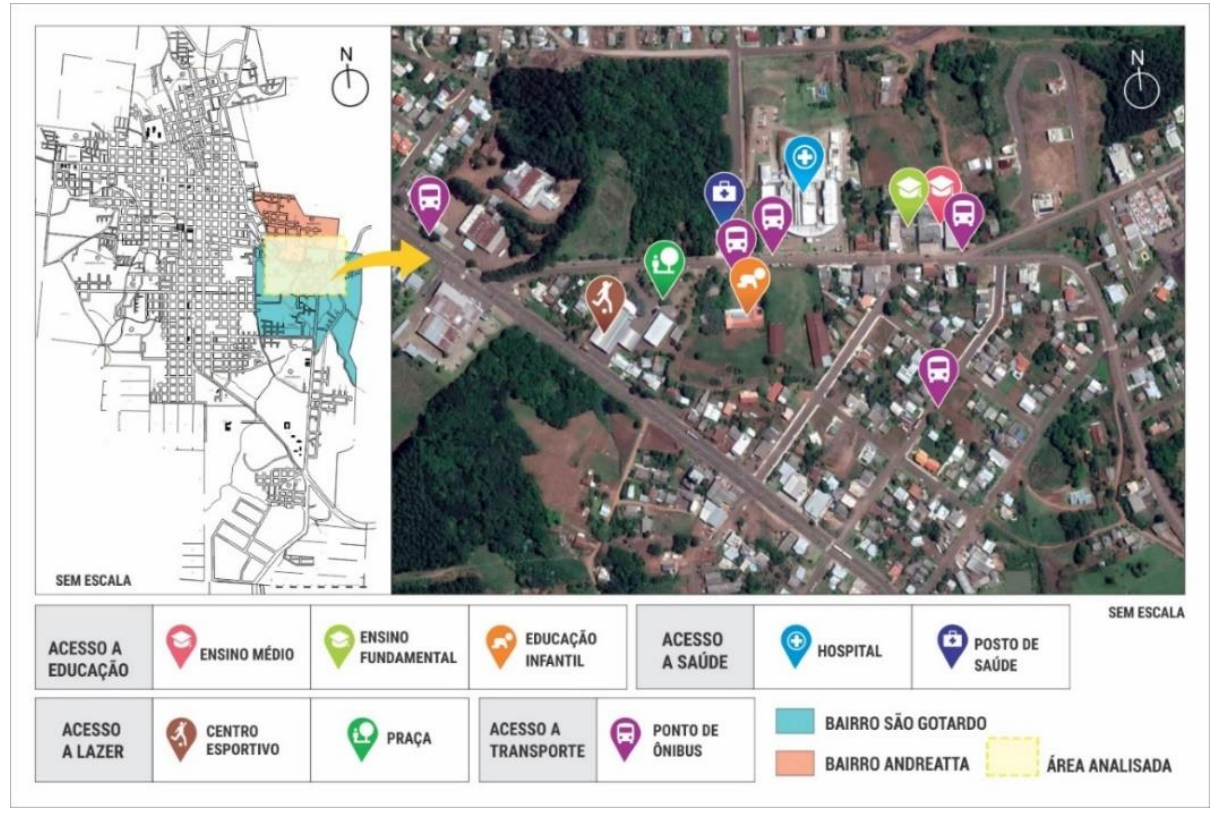

Fonte: Google Maps (2018), Prefeitura Municipal (2018), adaptado pelos autores

A região em torno do Hospital Regional Terezinha Gaio Basso possui diversos equipamentos comunitários e serviços e contempla além de equipamentos de saúde, equipamentos educacionais, lazer e transporte público. Apesar disso, apresenta baixa ocupação urbana.

Ao diagnosticar a oferta de equipamentos, percebe-se que nesta área há diversos lotes passíveis de implantação de conjuntos habitacionais, a fim de possibilitar uma inserção que garanta sustentabilidade social. Para a verificação das relações entre os lotes disponíveis e os equipamentos comunitários, utilizou-se padrões consagrados na literatura. Assim, temos na figura 04 a localização dos equipamentos comunitários e os respectivos raios de abrangência dos equipamentos. Para os equipamentos educacionais, de ensino médio utilizou-se o raio de Castello (apud ESCOBAR, 2016) ou seja 800 metros e educação infantil com raio de 400 metros. Já para os equipamentos de saúde, utilizou-se o raio de Pitts (apud ESCOBAR, 2016) para hospitais (raio de 5.000 metros), e para postos de saúde o raio de Castello (apud ESCOBAR, 2016) de 800 metros. Para a categoria lazer o parâmetro foi Prinz (apud ESCOBAR, 2016) onde os equipamentos como clubes desportivos usa-se o raio de 500 metros, e praças o raio de 400 metros. 


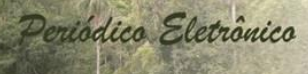 orum Ambiental
}

Volume 14, Número 5, 2018

\author{
da Alta Paulista
}

ISSN 1980-0827

Figura 04 - Raio de abrangência dos equipamentos urbanos
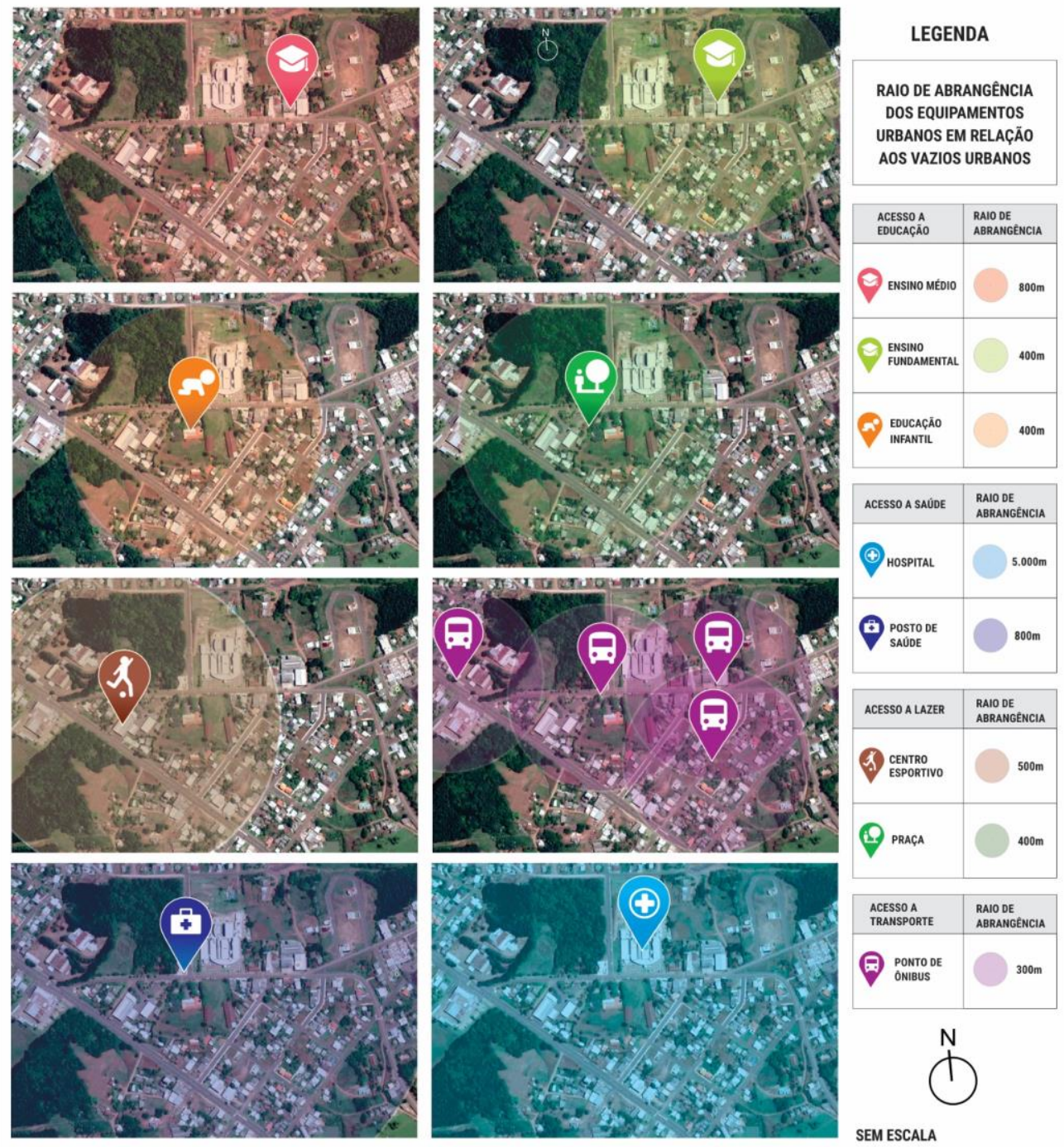

Fonte: Prefeitura Municipal (2018), adaptado pelos autores (2018)

A área em análise apresenta os equipamentos urbanos em raios de abrangência condizentes para um urbanismo mais sustentável, que infelizmente não está sendo ocupado por edificações e habitações, mas sim por vazios urbanos. Como ação municipal esta área deveria receber uma análise urbana detalhada onde haveria o levantamento de quais lotes estão cumprindo a função social do lote. Para cumprir a função social a propriedade deve atender simultaneamente no mínimo, conforme o Art 6이 do Plano Diretor:

I - intensidade de uso adequada à disponibilidade da infra-estrutura urbana de equipamentos e serviços;

II - uso compatível com as condições de preservação de qualidade do meio ambiente, da paisagem urbana e do patrimônio cultural;

III - aproveitamento e utilização compatíveis com a segurança e saúde de seus usuários e da vizinhança. (SÃO MIGUEL DO OESTE, 2011) 
Logo, ao diagnosticar todos os lotes que não estão cumprindo sua função urbana, o município poderia fazer a aplicação dos instrumentos de política urbana presentes no Plano Diretor, expresso nos Art. 8을 do Plano Diretor, referente ao Imposto Progressivo, e no Art. 12으, parcelamento, edificação ou utilização compulsório.

Art. 8 [...] VI- Imposto progressivo no tempo sobre a propriedade territorial urbana, seguido de parcelamento e edificação compulsórios e desapropriação com pagamento mediante título da dívida pública, de acordo com o art. 182, § 40 da Constituição Federal e Lei Federal no 10.257 de 10 de julho de 2001 (SÃO MIGUEL DO OESTE, 2011).

Art. 120 Será aplicado o parcelamento, edificação ou utilização compulsória, de que trata o art. 182, § 40 da Constituição Federal, incidentes sobre os imóveis que não estejam atendendo à função social da propriedade urbana, [...] (SÃO MIGUEL DO OESTE, 2011).

Assim, caso o proprietário não cumprisse com sua obrigação legal de edificar no imóvel, conforme o Art. 12으. parágrafo 5, o Município poderia desapropriar o terreno, podendo facultar a sua alienação a terceiro que comprometeria então a função social do lote (SÃO MIGUEL DO OESTE, 2011). .

Ao realizar a desapropriação, caberia ao município utilizar estes lotes para a aplicação de Zonas de Interesse Social, garantindo assim, não somente a relação da casa como abrigo, mas sim, a sustentabilidade social tão necessária às Habitações de Interesse Social, bem como, a sustentabilidade urbana ao fazer com que a população esteja inserida nos raios de abrangência dos equipamentos urbanos.

\section{CONCLUSÃO}

Este estudo ressalta que o desafio para as cidades brasileiras é ir além de reduzir o déficit habitacional buscando formas de promover o desenvolvimento sustentável das cidades, sem segregar, mitigando os impactos ambientais, trazendo qualidade nas habitações sociais (REIS e LAY, 2010). Uma forma possível para conseguir isso é utilizar os equipamentos comunitários como parâmetros de locação de Áreas de Interesse Social e buscar os vazios urbanos para implantação de HIS, promovendo a densificação de áreas com melhor infraestrutura.

Estudos mostram (KEELER; BURKE, 2010) que bairros e comunidades densas com alta conectividade permitem que as pessoas caminhem até o trabalho, escolas e ao demais recursos da comunidade, estes confortos públicos são essenciais para atender as necessidades culturais, sociais e físicas das pessoas, podendo ser umas das principais razões para que as pessoas escolham permanecer ou investir no bairro.

Nesse sentido, a promoção de habitações sociais em vazios urbanos tem também como objetivo consolidar o cumprimento da função social da propriedade, a fim de promover o acesso das famílias de baixa renda à terra urbanizada, dedicando uma parte dos terrenos 
urbanos que estão sem uma destinação social. Além disso, a utilização desses espaços subutilizados evita que a cidade se direcione a distâncias inconvenientes, o que acaba onerando o transporte público, dificultando assim o acesso dos serviços públicos às pessoas.

Repensar a forma com que as habitações sociais são vistas e inseridas no meio urbano é de fundamental importância não apenas para a mitigação da segregação social nas cidades brasileiras, mas também como promoção de uma cidade mais compacta e sustentável, principalmente em termos sociais.

\section{REFERÊNCIAS BIBLIOGRÁFICAS}

BENETTI, Pablo. Habitação social e a cidade: Desafios para o ensino de projeto. Rio de Janeiro: Rio Books, 2012. 104 p.

BORDE, Andréa de Lacerda Pessôa. Vazios urbanos: Perspectivas contemporâneas. 2006. 226 f. Tese (Doutorado) Curso de Arquitetura e Urbanismo, Universidade Federal do Rio de Janeiro, Rio de Janeiro, 2006.

BRASIL. Estatuto da Cidade: Lei 10.257/2001 que estabelece diretrizes gerais da política urbana. Brasília, Câmara dos Deputados, 2001.

BRASIL. Lei no 6.766, de 19 de novembro de 1979. Dispõe sobre o Parcelamento do Solo Urbano e dá outras Providências. Disponível em: <http://www.planalto.gov.br/ccivil_03/leis/L6766.htm>. Acesso em: 15 jun 2018.

CADONÁ, Marco Andre; TIRELLI, Cláudia; AREOSA, Sílvia Virgínia Coutinho. Políticas habitacionais, segregação residencial e desigualdade no acesso às políticas públicas: uma análise a partir do acesso a serviços públicos de saúde / Housing policies, residential segregation and inequality in access to public policies. Redes, [s.l.], v. 22, n. 1, p.326-345, 31 dez. 2016. APESC - Associacao Pro-Ensino em Santa Cruz do Sul.

CECCHETTO, Carise Taciane et al. Habitação de Interesse Social: Alternativas Sustentáveis. Revista Gestão e Desenvolvimento em Contexto - GEDECON, [S.n.], v. 3, n. 2, p.35-49, 2015.

DAIPRAI, Leandra. Mobilidade urbana: uma análise a partir do transporte coletivo urbano na cidade de São Miguel do Oeste - SC. 2017. 147 f. Dissertação (Mestrado) - Curso de Arquitetura e Urbanismo, Universidade Federal Tecnológica do Paraná, Pato Branco, 2017.

ESCOBAR, Fernanda de Bittencourt et al. IV ENANARQ. Inserção urbana e o PMCMV: a localização dos Moradores do condomínio Jardim Paraíso. Porto Alegre. 2016

FARR, Douglas. Urbanismo Sustentável: desenho urbano com a natureza. Porto Alegre: Bookman, 2013. 326 p. Tradução: Alexandre Salvaterra.

FREITAS, Verônica de; BARON, Cristina Maria Perissinotto; GABRIEL, Marcos Faccioli. SIMULAÇÃO DE HABITAÇÃO SOCIAL EM UM VAZIO URBANO CENTRAL. Revista Nacional de Gerenciamento de Cidades, São Paulo, v. 3, n. 14, p.128-146, 2015. Disponível em:<http://www.amigosdanatureza.org.br/publicacoes/index.php/gerenciamento_de_cidades/article/view/941/96 4>. Acesso em: 08 mar. 2018.

GOMIDE, Alexandre de Ávila. Transporte urbano e inclusão social: elementos para políticas públicas. Brasília, DF: IPEA, 2003.

IBGE, Instituto Brasileiro de Geografia e Estatística. Regiões de influências das cidades 2007. Rio de Janeiro: IBGE, 2008.

JOURDA, Françoise-hélène. Pequeno manual do projeto sustentável. Barcelona: G. Gilli, Ltda, 2012. 96 p.

KEELER, Marian; BURKE, Bill. Fundamentos de projeto de edificações sustentáveis. Porto Alegre: Bookman, 2010. 362 p. Tradução: Alexandre Salvaterra 
MOREIRA JUNIOR, Orlando. Segregação Urbana em Cidades Pequenas: Algumas Considerações a Partir das Escalas Intra e Interurbana. Raega - 0 espaço geográfico em análise, Curitiba, v. 20, p.133-142, 31 dez. 2010. Universidade Federal do Paraná. http://dx.doi.org/10.5380/raega.v20i0.20617. Disponível em: <http://revistas.ufpr.br/raega/article/view/20617/13764>. Acesso em: 02 abr. 2018.

OLIVEIRA, Patrícia Dalmina. A rede urbana no Extremo Oeste Catarinense: Uma reflexão sobre sua formação. Dissertação (Mestrado). Universidade Federal de Santa Catarina (UFSC): PGAU-Cidade, Florianópolis, SC: 2016

PALERMO, Carolina. Sustentabilidade social do habitar. Florianópolis: da Aurora, 2009. 96 p.

PEREIRA, Elson Manuel. Planejamento urbano no Brasil: conceito, diálogos e práticas. 2. ed. Chapecó: Argos, 2013. $325 \mathrm{p}$.

REIS, Antônio Tarcísio da Luz; LAY, Maria Cristina Dias. O projeto da habitação de interesse social e a sustentabilidade social. Ambiente construído, Porto Alegre, v. 10, n. 3, p.99-119, 2010. Trimestral. Disponível em: <http://seer.ufrgs.br/index.php/ambienteconstruido/article/view/12816/9721>. Acesso em: 10 mar. 2018.

SANTOS, Maria Paula Gomes. O Estado e os problemas contemporâneos. Brasília: CAPES, 2009. 144p.

SÃO MIGUEL DO OESTE. Lei complementar $\mathbf{N}^{\circ}$ 002/2011, 22 de dezembro de 2011. Dispõe sobre normas relativas ao Plano Diretor do município de São Miguel do Oeste, estado de Santa Catarina e dá outras providências. Disponível em: <https://leismunicipais.com.br/plano-diretor-sao-miguel-do-oeste-sc>. Acesso em: 09 jun. 2018.

SÃO MIGUEL DO OESTE. O município: Mapas. 2014. Disponível em: <https://www.saomiguel.sc.gov.br/municipio/15/mapas>. Acesso em: 05 jun. 2018.

SAUGO, Andréia; MARTINS, Marcele Salles. A sustentabilidade social e os novos projetos de empreendimentos habitacionais. Oculum ensaios, Campinas, p.102-115, 2012. Disponível em:

<http://periodicos.puccampinas.edu.br/seer/index.php/oculum/article/view/1454/142>. Acesso em: 13 abr. 2018.

SCHAFER, K. L. Forma urbana e equipamentos comunitários como referenciais na elaboração de Projetos urbanísticos: O caso de Navegantes - SC (Mestrado). Universidade Federal de Santa Catarina (UFSC): PGAU-Cidade, Florianópolis, SC, 2012.

VILLAÇA, Flávio. Espaço intra-urbano no Brasil. 2. ed. São Paulo: Studio Nobel: Fapesp: Lincoln Institute, 2001. 376 p.

WERNA, Edmundo et al. Pluralismo na habitação: Baseado nos resultados do Projeto "O Novo Papel do Estado na Oferta de Habitação: Parceria entre agentes públicos e não públicos" convênio 63.960737 .00 - Finep. São Paulo: Annablume, 2001. 300 p. 